\title{
Paranoya: Bir Vaka Degerlendirmesi ve Klinik Uygulamalardaki Farklilklar
}

\author{
Sinem Atmaca* \\ Orta Dogu Teknik Üniversitesi
}

\begin{abstract}
Özet
Paranoya, bireyin kötülüge ya da zarara ugrayacagı korkularına dayalı bir düçünce içerigidir. Bu düçünce biçiminde te melyapıo larak yansıtma mekanizmas ının izleri görülmektedir. Melan ie Klein ku ra mında, yans ıtma mekanizmas in 1 ve bir bebegin paranoid-çizoid konu mdan depresif konu ma ilerleyiçini ele almıçtır. Bu yazıda, önce Klein'ın belirttigi bu geçiçin nasıl gerçekleçtigi Freud ve Lacan'm yazıları ile ele alınmç, sonras ında paranoid kiçilik örgütlen mesinde bir vaka ilg ili yazın kapsamında incelen miçtir. Yazının sonunda ise, paranoid düçünce içerigine sahip sınır ve psikotik boyutta bulunan bireylerle ile ve yine paranoid düçünce içerigine sahip ancak nevrotik boyutta bulunan bireyler ile yürütülen terapi süreçlerindeki farklllıklar incelenmiçtir.
\end{abstract}

Anahtar Kelimeler: paranoya, yansıtma, paranoid çizoid konum, psikolojik esneklik.

*Iletiçim: sinematmaca7@gmail.com
Gönderim Tarihi: 05.05.2016

Kabul Tarihi: 24.08.2016 


\section{Paranoya: Bir Vaka Degerlendirmesi ve Klinik Uygulamalardaki Farklılıklar}

Paranoya, kiçinin, baçkası tarafindan kötülük görecegine dair bir düçünce içerigidir. Bu düçünce içerigine sahip bireyler kendilerine saldırılacagı, küçük düçürülecegi, aldatılacagı ya da açagılanacagına dair korkular duyabilir. Genelde çüpheci, bir çeyi alt etmeye çahı̧an, ya da bir kötülükten kaçan kiçiler olarak görünürler. Bazları daha içe çekilmiç pozisyondayken, bazları daha aktif olarak hayatın içinde olabilirler. Birçok kitap ve filmde bu karakter örgütlenmesindeki bireylere rastlamak mümkündür.

Paranoid içerikli düçünceye sahip bireylerde en temel ya da diger ifadeyle yüzey yapının yansıtma mekanizması oldugu belirtilmektedir (McWilliams, 1994). Daha ilkel bir savunma mekanizması olarak tanımlanan yansitmada, birey kendinde var olan duygu ve düçünceleri karçıdaki kiçilere aktararak bu özellik lerin onlarda oldugunu düçünür. Bu yolla aslında, bireyin altta yatan arzularını (desire) bastırdıgı, kapattıgı belirtilmektedir. Örnegin, arzusu/istegi/düçüncesi 'ben bu adamı sevmiyorum, ondan nefret ediyorum' olan kiçinin, yansitma mekanizması ile düçüncesi 'o benden nefret ediyor' a dönüçtürülür. Yansitılanın içe alınması ile de (projective identification) 'ondan nefret ediyorum çünkü o benden nefret ediyor'a dönüçen düçünce tekrar yansitılır. Böylece, ilk arzunun üstü skıı skkıya kapatılmıç olur. Paranoid düçünce içerigine sahip bireylerin de, kendilerinde olumsuz olarak gördügü özellikler ile paranoid içerikli yansitma (projection) yaparak baça çkmaya çalçıyor olabilecekleri belirtilmiçtir. Freud paranoid içerikli düçünceye sahip bir danıçanı olan Schreber Vakası'nda bastırımıç arzuların yansıtma ile nasıl yön degiçtirdigini aktarmıçtır (Melman, 2009).

Yansitma mekanizmasını ele alırken Melanie Klein'ın çalıçmalarının önemli bir yer tuttugu belirtilmektedir (Tura, 1998). Klein (1937) kuramında, insanların temelde, yok olma (paranoid kaygi) ve terk edilme (depresif kaygı) dedigi iki tür kaygı ile mücadele ettigini belirtmektedir. Bebek ilk günlerde, annesinin onun her istegini yerine getirmesi sonucunda, kendisinin yani arzusunun her çeyi oluçturan oldugunu düçünmektedir. Tüm güçlülük adını verdigi bu evrede bebek mutlak güçlü iken, zamanla her istediginde annesinin orada olamaması gerçekligi ile karçılaçır. Klein'a göre, Ötekinin varlıgını hissettigi bu dönemde bebek, bir kutupta kendini sevgi içinde yüzüyor hissederken, diger kutupta cezalandırıldıgını düçünür. Bunun iyi meme ve kötümemenin gelme anlarına denk düçtügü belirtilmektedir. Bebek iyi memeyi sever ve onu korumak isterken, kötü memeden nefret eder ve yıkıcı intikam fantezileri ile içini doldurur. Klein (1957), insanın, kötü niyetin kendi içinde oldugunu hissetmektense, dıçnda bir nesnede oldugunu hissetmeyi daha az tehlikeli buldugunu, bu nedenle kiçiligin bu istenmeyen yanlarının dıça atıldıgını ve kötü memeyi (kötü nesneleri) yarattıgını belirtir. Düçünce olarak 'beni yok etmeye çalçan bir kötü meme var ve ben de bu kötü memeden kaçmaya ve hatta onu yok etmeye ugraçıyorum' temeldir. Bu açamaya paranoidçizoid konum adını veren Klein, zamanla -daha saglklı çevrelerde büyüyen bebeklerin- bu paranoid-çizoid konumdan depresif konuma dogru geçtigini belirtmiçtir (Mitchell, \& Black, 1994).

Klein'ın kuramı degerlendirildiginde akla çöyle bir soru gelmektedir: Tüm bebekler, aslında tüm güçlülük evresinden geçip anneden ayrılıç anını yaçamaktaysa, neden ve nasıl bazı bebekler depresif konuma dogru ilerleyebilirken digerleri paranoid-çizo id evrede kalmaktadır; bu 'daha iyi çevre' etkisi ile bebek neyi yapabilmektedir? Bu durumu açklamada fort-da oyununun ele alınabilecegi düçünülmüçtür. Freud, torununun durmadan tekrar ettigi fort-da oyununda, çocugun anneyi bulup kaybetme durumunu kendisi yaratarak, annenin ortadan kaybolmasının yarattıgı etkiyi telafi ettigini belirtir (Aktaran, Lacan, 1964). Bizim kültürümüzdeki ‘ce’ oyunu ile benzer oldugu düçünülebilir. Jacques Lacan’a göre (1964), bebek, anneyi bir süreligine kaybeder ve sonra tekrar bulur, kaybeder ve tekrar bulur. Bu açamada zamanla bebek anneyi kaybetme anlarına ait olumsuz duygularını düzenleme becerisi edinmeye baçlayacaktır. $\mathrm{Bu}$, -annenin kaybı ya da gelmeyiçi sırasında oynanan oyunlarla- kendini sakinleçtirme ve duygularını regüle 
edebilme çeklindeki psikolojik esneklik becerisinin geliçiminin, bebegi paranoid konumdan daha geliçmiç depresif konuma dogru ilerlettigi düçünülebilir. O halde, bu konuma geçemeyen bireylerin, annenin kayboluç anlarında bu psikolojik esneklik becerisini geliçtiremedigi söylenebilir.

Lacan (1964), Klein'ın paranoid-çizoid olarak tanımladıgı ilk evre ile benzer zamanlarda, bebegin zihninin anneden ayrıçmamıç oldugunu vurgular. Birincil narsisizm denilen bu evrede, bebek anneden -Ötekinden ayrı beden bütünlügünde, ayrı bir yapıda kendisini hayal edemez. Zihninin ve bedeninin digerinden ayrıçmamıç olması sonucunda, ötekinin zihni kendi zihni, kendi zihni de ötekinin zihni olarak görünür. Paranoid düçünce içerigine sahip psikotik boyuttaki danı̧anlarda görülen 'zihnimi okuyacaklar, bendekini bulacaklar, aklımı yönetecekler' düçünceleri, Öteki ile ayrıçmamıç bir zihnin emarelerini göstermekted ir. Ikincil narsisizm evresinde ise bebegin, ötekinin varlıgından biraz da olsa kendini ayrıçtırabildigi ve Ötekinin arzu ettigi nesne/özne konumuna dogru ilerledigi söylenmektedir (Lacan, 1964).

Paranoid düçünce içerigine sahip bireylerde McWilliams (1994) ise, özellikle küçük düçürülme (humuliation) anlarmın ve duygusunun önemli yer tutugunu vurgular. Bu bebeklerin her an tehdide ugrayacakları endiçesi zihinlerinde her yeri kaplamaktadır der.

Açagıda paranoid düçünce içerigine sahip bir vaka ile yapılan görüçmeler belirtilen yaklaçımlar ile yeniden ele alınacaktır. Ardından McWilliams'ın paranoid düçünce içerigine sahip ve psikotik boyuta yakın olan bireylerle yürütülen terapi sürecinin, standart olarak denilen nevrotik danıçanlarla yürütülen klinik uygulamalardan farkh oldugunu vurguladigı noktalar ele alınacaktır.

\section{Saniye Hanım}

Saniye Hanım ünitemize ilk baçvurdugunda 21 yaçında 1. sınıf ögrencisiydi. Ilk çikayetleri ders çalıçamama, internette sahte hesaplar açarak itiraf sitelerine girme, gizli numaralar ile insanlarla tanıçma ve yaçadıklarını arkadaçlarına anlatmaktan kendini alkoyamama ve kimseye hayır diyememeyi içermekteydi. 35 seanslık terapi sürecine ait seans degerlendirme raporlarında ilk terapisti, önceleri davranıç düzenleme ve öfke ifade etme çalıçmalarına odaklanıldıgını, ancak bu düzen ve plan tablolarına danıçanın uymaması sonucunda sonraları aile süreçlerini ele alan çema odaklı bir yaklaçıma yöneldigini belirtmiçti.

Saniye Hanım, ilk terapisini bırakmasının beç ay sonrasında ünitemize ikinci kez baçvurmuçtur. Ilk terapistinin uygun yerinin olmadıgının söylenmesinin ardından, ikinci terapiste ataması yapılmıçtır. 23 görüçmelik bu ikinci sürecin ilk görüçmesine yaklaçık sekiz dakika boyunca aglayarak baçlayan Saniye Hanım, kendisini neyin üzdügü soruldugunda ses kayıt cihazını istemedigini belirtmiçtir. Sebebi soruldugunda, önceki terapilerde kayit cihazı yüzünden bazı çeyleri anlatamadıgını, çimdi anlatmak istedigini ama ailesi ile ilgili anlatacagı çeylerin duyulacagından, kayitların bir çekilde ailesinin eline geçeceginden endiçelendigini söylemiçtir. Egitim sürecinin bir parçası olarak kayıt cihazının kullanılacagı belirtilmiç ve görüçmelerin bu biçimdeki devamlılıgı hakkındaki kararın ikinci görüçmede ele alınabilecegi söylenmiçtir. Ikinci görüçmede Saniye Hanım'ın korku ve kaygilarının ele alınmasının ardından kayıtların paylaçımının danıçanların istememesinin yanı sıra, kurumun ve terapistin de kendi güvenligi açısından verilmeyecegi belirtilmiçtir. Bunun üzerine Saniye Hanım biraz rahatlamıç ve cihazın kullanımı ile görüçmeler sürdürülmüçtür.

Saniye Hanım' in temel yakınmaları, özellikle kız arkadaçlarının kendisinin her çeyini çok kıskanmaları ve bu nedenle kendi ifadesi ile onun kuyusunu kazmalarına dair düçünceleri hakkında olmuçtur. Sınıfını üç yıldır tekrar ediyor olsa da, asında kendisinin çok baçarılı ve arkadaçlarından üstün biri oldugunu, diger insanların kendisi ile yarıçamayacagını, çünkü aynı seviyede bile olmadklarını düçünmektedir. Bu çok iyi özellikleri nedeni ile tüm insanların kendisinin iyi özelliklerini almaya çalıçtıklarını, örnegin yurt arkadaçlarının parfümünü çok begendiklerini ve devamlı olarak parfümünün ismini sorduklarını; odasına geldikleri zaman makyaj malzemelerini ya da oje numaralarını karıçtırdıklarını; 
onun olan her çeyi elde etmeye çalıçtıklarını kızgnlıkla anlatmaktadır. Bugüne kadar erkek arkadaçı olmayan Saniye Hanım, bu durumu, kadın arkadaçları yüzünden erkeklerin kendisine yanaçamadıgı düçüncesi ile yogun çekilde iliçkilendirmekted ir: 'Kadınlar erkekleri elde etmek için strateji yapan 'sinsiler', erkekler ise bu tuzaklara düçen 'saflar', bu sinsiler yüzünden bana yaklaçamıyorlar, ben strateji yapmıyorum' çeklinde ifadelerini skklkla getirmektedir. Bu iyi özelliklerinin elde edilmeye çalıçıldıgı biçimindeki kaygı ve korkularının lise döneminde de oldugu görülmüçtür. Saniye Hanım, üniversiteye hazırlanırken arkadaç grubundan gizli olarak etüt (ek ders) aldıgını dile getirmiç, lise arkadaçlarının da kendisinin baçarısının önüne geçmeye çalıçtıklarını belirtmiçtir. Bu korkuları nedeni ile eçyalarını ortalıkta bırakmadıgını, parfümünü kimseye göstermeden gizlice sıtıtıını, yakın arkadaçlarından bilhassa gizli olarak ögrenci topluluklarına katıldıgını belirtmiçtir.

$\mathrm{Bu}$ gizlilik davranıçı ile iyi özelliklerini korumaya çalçan Saniye Hanım, ayrıca yakın arkadaçlarının 'sinsiliklerini' ya da kötü görünebilecek durumlarını, özellikle onların iyi oldugu arkadaçlarına anlattıgını, onların sinsiliklerini bozdugunu belirtmiçtir. Örnegin, yakın bir arkadaçı ile birlikte yeni bir erkek ile sohbet etmek için oturduklarında, arkadaçının Saniye Hanım'1 hiç düçünmeden hemen o kiçiye asıldıgını, çokça sevgili yapmak istedigini, o erkegi ayarlamak için hiç hoçlanmadıgı filmleri ya da kitapları okumuç, izlemiç gibi yaptıgını belirtmiçtir. Bu durumda arkadaçının o filmi hiç izlememiç oldugunu ya da sevmedigi çeyi gün yüzüne çıkardıgını söylemekted ir.

Genel olarak 'kimseye hayır diyemedigini' ve 'sevmedigi birçok insanla iyi geçindigini' belirten Saniye Hanım ilerleyen görüçmelerde bu hayır diyememe davranıçını "eger arkadaçlarım ile kavga edersem, onlar, digerleri hakkında anlattıgım dedikoduları benden hınç almak için aleyhimde kullanabilirler" çeklinde korkularından dolayı gerçekleçtigi çeklinde dile getirmiçtir. Bu nedenle, aslında önceki öfke ifade çalıçmalarının bir saçmalık oldugunu, çükü onlarla arasını iyi tutmak zorunda oldugunu, önceki terapistini kıdırmamak için bu çalçmalara uyum sagladıgını belirtmiçtir. Yeni terapistine ise kendisinin daha iyi anlaçıldıgına dair, 'daha iyi' temalı birçok övgü sunmuçtur.

$\mathrm{Bu}$, herkesten çok iyi oldugu düçüncesinin tersine Saniye Hanım, adından ve soyadından nefret ettigini aglayarak belirtmiçtir. Adının babaannesinin adı olması, babaannesinden nefret etmesi, çünkü babaannesinin dedikoducu oldugu çeklinde bir zincir ile bu duygularını baglamaktadır.

Saniye Hanım' in ailesi ile ilgili bilgiler alındıgında, Güney Anadolu'da yaçayan 5 kı 1 erkek kardeçli bir ailenin en büyük çocugu oldugunu belirtmiçtir. Annesi ev hanımı, babası memurdur. Ailesine çok kızgın oldugunu, babasının kardeçlerine çok yüz verdigini, özellikle küçük erkek kardeçine kural koymadklarını aglayarak dile getirmiçtir. Annesinin çımarıklık yapan kardeçlerinin bütün isteklerini yapan bir melek olmasına oldukça kızgındır. Örnegin kendisinin yemek ayırt etmedigini, her çeyi yemeye çalıçtıgını, ancak bir kardeçinin bulgur digerinin sarımsak istemedigini ve annesinin de tüm bu çımarklık lara uydugunu kıgınlıkla dile getirmektedir. Bunları yapmaması için onu kaç kere uyardıgını belirten Saniye Hanım ayrıca ailesinin çimdiki ekonomik zorlanmalarını önceden hesaplayı bu kadar çocuk yapmamaları gerektigini düçünmeleri gerektigini belirtmektedir.

Babası ile ilgili olarak ise, yaçadıkları yerdeki erkeklerin ve babasının, sürekli çakayla karıçık Suriye'den kadın getiririm dedigini, bu nedenle erkeklerden ve erkek kardeçinden tiksindigini dile getirmiçtir. Sonraları babasının kız kardeçine tecavüz ettigini 'anlatmam gereken bir çey var' diyerek getiren Saniye Hanım'a kardeçinden duydugu bu olay ile ilgili bilgiler soruldugunda (gizlilik açısmdan genel özellikler verilecektir) kendisinin yaz tatilinde eve gittigi zamanda oldugunu, kardeçinin babasının üç gece yanına geldigini söyledigini anlatmıçtır. Bu seansta dikkat çeken nokta Saniye Hanım'ın kardeçine üzgün yerine kızgın oluçu -Kardeçine "o an neden bagırmadın, neden ses çıkarmadın, ben içerdeydim, bizi çagirsaydın” diyerek çokça kızdıgını belirtmiçtir, ve 'baçıma bu nasıl geldi' diyerek aglayıçı olmuçtur. 


\section{Vakanın Kuramsal Açıdan Degerlendirilmesi}

Saniye Hanım' ın temelde düçünce içeriginin diger insanların kendisine zarar vermeyi istedikleri ve iyi özelliklerini elinden almaya çalıçtıkları biçimindedir. Bu düçüncelerin Saniye Hanım'ın kendi içinde olan 'ben diger insanlardan nefret ediyorum' düçüncesinin birer yansıması oldugu düçünülmektedir. Bu yansımanın içe alınması ile düçüncesinin 'onların benden nefret ettigini görüyorum, bana zarar vermeye çalıçtıkları için de ben onlardan nefret ediyorum' çekline dönüçtügü düçünülmekted ir.

Bir yandan çok iyi özelliklere sahip oldugunu vurgulayan Saniye Hanım, diger yandan adından ve soyadından dahi nefret ettigini belirtmektedir. Bu nefret ettigi ismin babaannesinden gelmesi, onun nefret ettigi özelligi olan dedikoduculugu yapması, onunla özdeçim kurdugu kötü yanlarına yaptıg1 atıflar olarak görülebilir. Kendisini bir yandan iyi biri olarak tanımlamakla yogun ugraç içinde görünürken, diger yandan kötülüklerle dolu bir temeli olduguna dair yogun inançları oldugu söylenebilir.

Saniye Hanım' ın, baçkalarının, kendisinin elindeki iyi özelliklerini elinden alacagı korkusunun Klein'ın tanımladıgı kötü memeye maruz kalma ya da kötü memenin gazabına ugrama çeklindeki kötülüge ugrama, cezalandırılma kaygilarına denk düçtügü düçünülebilir. Bu kötülüge ugrama ve cezalandırılma durumlarından korunmak için Saniye Hanım'ın gizli saklı davranıçlarda bulunma, kendine ait özelliklerini (oje, parfüm, kitap, topluluk) gizleme davranıçlarını sergiledigi düçünülmekted ir.

Saniye Hanım' ın iyi özelliklerini gizleyerek koruma davranıçlarının yanı sıra, tüm arkadaçlarına birbirlerinin dedikodusunu yapma durumu, iyi memeleri yok etmeye çahçan tahripkar bir haset duygusunun motivasyonları oldugunu düçündürmektedir. Arkadaçlarının iyi özellik olarak sundukları çeylerin aslında erkekleri elde etmek üzere yaptikları sinsilikler oldugunu onlara anlatan Saniye Hanm, bu tahribin görüleceginden de yogun çekilde endiçe ve suçluluk duymaktadır. Bu duygular nedeni ile de sevmiyor olsa da onlarla iletiçimini asla koparmaması ve hatta dedikodusunu yaptıgı arkadaçlarının hepsine birer pasta yapması, onların kendisini cezaland racagından yogun çekilde korktugunu ve bu kötü memelerin gelmesini engellemeye çalçtıgını düçündürmektedir.

Saniye Hanım' in seans baçında ses kayitlarının ele geçirilecegi, söylediklerinin duyulacagı, dedikodu yaptıgının yüzünden okunacagı gibi düçüncelerinin Öteki ile kurdugu iliçkide zihnini ötekinden ayrıçtıramamıç olduguna dair örnekler olarak düçünülmektedir. Annesinin diger kardeçleriyle ilgilenmesi esnasında yaçadıgı anne kaybında yaçadıgı olumsuz duyguları düzenleyememiç olabilecegi ve psikolojik esnekligi geliçtiremedigi düçünülmektedir. Lise dönemine kadar derslerinde baçarılar göstermiç olan Saniye Hanım, lisede bu düçünce içeriklerinin yogunlaçmıç oldugu arkadaçlarından gizli olarak etütler almaya baçlaması ile kendini göstermektedir. Üniversiteye geldiginde gizli hesaplar ve itiraf sitelerine girme davranıçları sonucunda iliçkilerinde artan karıçılıklar yaçayan Saniye Hanım'1n, derslerini ve belirli bir düzeni oturtamadıg1 görülmektedir. Ikinci terapi sürecinin sonunda da giderek yogunlaçan iliçkisel krizler ve ailenin maddi kaynagı kesmesi ile uzun uyku süreçlerine giren Saniye Hanım' in daha içe çekilen bir pozisyona dogru ilerledigi düçünülmektedir.

Saniye Hanım' in paranoid-çizoid konum veya birincil narsistik evre olarak tanımlanan bu konumunun, erken dönemlerde, çok fazla çocugun bulundugu bir ailedeki anne ile kurdugu iliçkiden yön bulmuç olabilecegi düçünülmektedir. Annesini bir yandan melek diye tanımlarken, babası ve erkeklerden tiksindigini belirten Saniye Hanım, aslında annesinin de bu melek yapısına öfkelendigini sonraları getirmiçtir. Kendisi dıçında, baçkalarma yönelen bu melek davranıçlara oldukça kızgn görünmektedir. Saniye Hanım, bu önemli-digerlerini konumlandırırken sılıkla bölme mekanizmasını kullanmasının buralardan gelmiç olabilecegi düçünülmektedir. Annenin hem ilgiyi kardeçlerine veren yapısından hem de babanın sapkılıklarına göz yummasından nefret eden Saniye Hanım, aynı zamanda annesinin gözünde iyi olmak da istemektedir. Bu iyi konumu kurmanın/korumanın, aynı arkadaçlarında oldugu gibi, diger 
kardeçlerini kötüleyerek oluçturabilecegini düçündügü görülmektedir. Bu kötüleme/bozma eylemleri ile de aslında içten içe cezalandırılma korkularının tekrar yeçerdigi düçünülmektedir.

\section{Saniye Hanım ile Yürütülen Terapi Süreçleri}

Saniye Hanım ile yapılan ilk terapi sürecinde, önceleri plan tablosu ve tavsiye istekleri ile gelen danıçana yönelik daha sempatik bir terapist karçı aktarımı içinde olundugu rapor edilmiçtir. Ancak sonraları terapist, çema odaklı bir yaklaçımla durumların kökenlerine inmeyi hedeflemiç oldugunu ve kendisinde daha negatif hislerin oluçtugunu belirtmiçtir. Bu süreçte danıçan dönem sonuna dogru içe çekilmiç, derslerini geçemedigi için uzun uyku evrelerine girmiç ve terapiyi bırakmıctır.

Ikinci terapi sürecinde de benzer biçimde danıçanın seanslara yogunca aglayarak baçlaması ve terapistin de ilk terapi deneyimi olmasının sonuçları olarak daha sempatiye kayan bir etkileçimin oluçtugu düçünülmektedir. Bu aglama krizlerini dindirme açamalarında daha destekleyici bir tarzda ilerlenmiçtir. Danıçanın ikinci terapistine övgüler sunmaya baçlamasından sonra, magdur oldugu anıları bırakmıç ve kötülük görme kayglarına karçı yaptıgı eylemleri getirmeye baçlamıctır. Bu kötülüge ugrayacagına dair düçünceleri, nevrotik boyutta düçünceler olarak ele alınmaya çalçılmıç, danıçanın bu düçüncelerinin içerigi, duyguları ve yaçantıları sorgulanmıçtır. Görünürde terapist ile iyi bir iliçki vurgusu olsa da, danıçanın zamanla savunma mekanizmalarının arttıgı ve terapistten de kötülük görebilecegine dair inançlarının geliçmiç olabilecegi düçünülmüçtür. Baçkalarına karçı verilen zararlara anlayıç gösterememeye baçlayan terapistin içten içe öfkeli duygular geliçtirdigi gözlenmiçtir. Süpervizyonlarda bu duyguların ele alınmaya baçlaması ile sempati ve empatinin ortalarında bir konum arayıçı olmuçtur. Ancak içerik olarak danıçanın davranıçlarının ele alınmasının her çekilde danıçanda yarglanma hisleri yarattıgını düçündürmektedir. Iliçki karıçılıkları, ailenin okuldan alma tehditleri ile yine ilk terapi süreci ile benzer dönemlerde danıçan terapilere gelmemiçtir. Bu sonlanmanın ardından, ilk terapist ile yapılan bir görüçmede süreçler degerlend irilmiçtir. Tavsiye isteyen bir kiçi olarak sürece baçlanıldıgı ancak sonras ında yarattıgı bu öfkelerin benzerlikleri üzerine konuçulmuç, danıçanın nevrotik düzeyde bir bireyden daha farkhı hisler uyandırdıgı paylaçılmıçtır. Sonrasında paranoid düçünce içeriginin, kötülük görmeye yönelik davranıçların kaçırıldıgı düçünülmüç, bir yazı ile danıçanın paranoya içerigi öne alınarak tekrar degerlendirilmesi hedeflenmiçtir. Bu baglamda, McWilliams (1994) paranoya semptomunun psikotik, sinırda ya da nevrotik olarak tanımladıgı her üç boyutta da yer alabilecegini belirtmiç ve paranoyanın psikotik ya da smırda düzeyde yapılan danıçanlarla yürütülen terapi ile nevrotik düzeyde bireylerle yürütülen terapiden farkh çekilde ele alınmasının önemini vurgulamıçtır. Bu farklılıklar açagıda ele alınmıçtır.

\section{Paranoid Kiçilk Örgütlenmesi ile Yürütülen Terapilerdeki Süreç Farklılıklan}

McWilliams (1994), paranoid düçünce içerigine sahip danıçanların 'diger insanlar bende gördükleri ve haset duydukları çeylerden dolayı benim peçimdeler' düçüncelerini dogrudan karçıdaki insana yansitmaları ve haset duygularına kapılmaya yatkın olmaları nedeni ile, en derinde, terapistin kendisini ve tüm kötülüklerini gerçekten tanıdıgında afallayacagını ve onu reddedecegini ve hatta cezalandıracagını düçünmelerine dogru ilerleyebilecegini vurgulamaktadır. Bu nedenle, standart denilen nevrotik düzeylerdeki terapi uygulamasının - danıçanı derin düzeyde anlama, kendiligin bilinmeyen yönlerini bilinç alanına getirme ve bir insan olarak farklı yönlerini kabul etmeye çalçmayı içeren biçim- paranoid kiçilik örgütlenmesine sahip bireylerde neredeyse imkansız oldugunu vurgulamaktadır. Bunun birinci nedeninin, zaten yüzeyde görünen duygunun çok köklü degiçimler göstermiç oluçudur denmektedir. Terapistin yüzeyde gördügü içerik çarpıtılmıç, dıça atılmıç, yansitılmıç ve yansitılan tekrar içeri alınmıçtır. Asıında bu görünenin altındaki itilmiç içerige kıyıdan köçeden bakabilmenin bile tüm yolları engellenmiç, zihne 
yabancılaçtırılmıçtır. Danıçanın sözlerine ve davranıçlarına iliçkin yorum yapmanın ve inkâr ve yansıtma mekanizmalarının ele alınmasının, bu savunmaların daha da karmaçık olarak kullanılmasına yol açtıgı vurgulanmaktadır. Terapistin danıçanın kendisine sordugu soruları cevaplamak yerine detaylandırması, davranıçlarının bilinçdıçı bir duyguyu belirttigi yorumunu getirmesi, sürçmelere dikkat çekmesi gibi klasik yaklaçımların danıçanı daha yüksek savunmalara götürdügü belirtilmektedir.

Bu katmanlı savunma süreçleri nedenleri ile paranoid özellikli kiçilerde mizahın (humor) önemli olabilecegi söylenmektedir. Ancak, mizahın igneleme gibi olmamasına özen gösterilmelidir, çünkü danıçanın bu durumda, kendisi ile dalga geçildigini düçünmesi oldukça olasıdır. Iyi-mizah biçimi olarak, terapistin kendi hata, zayıflık ve yapaylkkları ile dalga geçtigi durumlar vurgulanmıçtır. Bu duruma örnek bir yorumu McWilliams (1994) çu çekilde vermektedir: Tüm güçlülük inançları nedeni ile binecegi uçagin düçeceginden endiçe duyan bir danıçana 'Tanrı'nın sırf seni cezalandırmak için uçaktaki diger yüz insanın hayatını feda edecek oldugunu mu düçünüyorsun' biçimde bir yorumun daha terapötik olabilecegi söylenmektedir. Saniye Hanım' in ilk baçlardaki ses kayit cihazının kimseye verilmeyecegine inanamadıgı durumda, terapistin, bu kayıtları istememesinin nedenini anlamaya çalçmaktan çıkıp, bunun yerine "Kayıtların kimseye verilmeyecegine sizi ikna etmemi istediginizi düçünüyorum artı, ancak bunu yapmayacagım, çünkü bu durum sadece sizin gizliliginiz için degil, terapist olarak kendimin ve kurumumun da gizliligi için yapılmayacaktır" demesinin ardından Saniye Hanım'ın bir anda rahatlamıç olması bu duruma benzerlik göstermekted ir.

Temelde, terapistin aklındaki gizli bir planı yapmak yerine 'gerçekten' biri oldugunu gösterdiginde terapötik bir etki olabilecegi, kendisine yansitılmıç olan tüm öfkeleri bir kenara bırakıp ne kadar da yalnız ve destekten yoksun oldugu yorumu ile bu öfke dolu meselelerin kaynaklandıgı reddedilmiç ve yansitılmıç duygular üzerinde durabilmesi önemli bulunmuçtur. Ayrıca, terapi hedefinin tekrarlı vurgusu önemli görünmektedir. Aksi takdirde, paranoid içerikteki danıçanın, bu negatif- çüpheci düçüncelerin zihninden geçmemesi gerektigi varsayımına kapılabilecegi ve terapi hedefi olarak terapistin, bu kötülüklerinin atılmasinı hedefleyebilecegine inanabilir denmektedir (McWilliams, 2013).

$\mathrm{Bu}$ biçimdeki bir terapi süreci ile danıçan, Klein’ in tanımında oldugu gibi iyi ve kötü memeyi içeren anneyi, terapisti ve digerlerini birleçtirmeye baçlayabilir. Aslında insanın acı ve engellenmelerinin nedeni saf kötü niyet ve kötülük degil de, hata yapabilirlik ve tutarsızlık oldugunu görmeye baçlayabilir. Kötülük görme tehdidi azalınca, bölme yapmanın zorunlulugunun da azalacagı belirtilmektedir. Klein (1957), bu süreçte yalnızlık ve hayatın anlamlarına yönelik yeni korkuların oluçtugunu söyler. Ancak bu korkular bireyi daha ilkel olan paranoid-çizoid konumdan daha ileri düzey olan depresif konuma götüren bir içerikte olacaktır. 


\section{Kaynaklar}

Klein, M. (1937). Sevgi, suçluluk ve onarım. (A. A. Köçkdere, Çev.). B. Habip (Ed.) içinde, Sevgi, suçluluk ve onarm (2.basim). Istanbul: Kanat Kitap (1975).

Klein, M. (1957). Haset ve Çükran (O. Koçak ve Y.Erten, Çev.). Istanbul: Metis Yayınları. (2014).

Lacan, J. (1964). Psikanalizin Dört Temel Kavramı: Seminer ll. Kitap. (N. Erdem, Çev.). Istanbul: Metis Yayınlar1 (2013).

McWilliams, N. (1994). Psikanalitik Tanı: Klinik Süreç Içine Kiçilik Yapısını Anlamak (E. Kalem, Çev.). Istanbul: Istanbul Bilgi Üniversitesi Yayınları. (2013).

Melman, C. (2009). Schreber's Lack of Lack. The Letter, 40, 83-91. Retrived from www.lacaninireland.com

Mitchell, S. A., \& Black, M. J. (1995). Freud ve Sonrast: Modern Psikanalitik Düçüncenin Tarihi (A. Egilmez, Çev.). Istanbul: Istanbul Bilgi Üniversitesi Yaymları. (2014).

Tura, S. M. (1998). Editörün önsözü. M. Klein, Haset ve Çükran içinde, (O. Koçak ve Y. Erten, Çev.; ss. 7-13). Istanbul: Metis Yayınları. 


\section{Summary}

\section{Paranoia: A case Example with Differences in Clinical Applications}

Paranoia is a kind of thinking content that is based on the person's fear of being damaged or injured. The underlying structure of this thinking content is related with the mechanism of projection. Melanie Klein, in her theory, reviews the progress from paranoid-schizoid position to depressive position of the babies. In this paper, first the progress that was theorized by Klein was examined from Freud' and Lacan' perspectives, and then a patient with paranoid personality organization was analyzed based on these perspectives. Lastly, the differences between the therapies conducted with people who have the paranoid characteristics in the borderline and psychotic position and with the neurotic patients were examined.

Keywords: paranoia, projection, paranoid schizoid position, psychological flexibility. 